\title{
Increasing the Awareness of Autism Spectrum Disorder with Training of Pre-School Teachers and School Counselors in Turkey
}

\author{
Halil Kara ${ }^{1}$ Mehmet Semih Demirtaş2® \\ ${ }^{1}$ Child and Adolescent Psychiatry Institute, Aksaray University Faculty \\ of Medical Sciences, Aksaray, Turkey \\ 2 Faculty Pediatrist, Faculty of Medicine, Aksaray University Medical, \\ Aksaray, Turkey
}

\begin{abstract}
Address for correspondence Halil Kara, Aksaray University, Aksaray Faculty of Medicine, Aksaray Training and Research Hospital, Child and adolescent psychiatry clinic, Aksaray, 68100, Turkey (e-mail: drhalilkara85@gmail.com).
\end{abstract}

\author{
Abstract \\ Keywords \\ - autism spectrum \\ disorder \\ - teacher training \\ program \\ - vaccines \\ - thimerosal substance
}

Training programs for the awareness of autism for professions are supported under the leadership of the United Nations. Misinformation can cause socially destructive results as that which is incorrect is assumed to be known correctly. This study included a total of 308 participants comprising $226(73.4 \%)$ preschool teachers and 82 (26.6\%) school counselors. The basic questions related to the awareness and knowledge of autism spectrum disorder (ASD) were selected based on the Diagnostic and Statistical Manual of Mental Disorders, Fifth Edition (DSM-5) and the Autism Diagnostic Observation Schedule, Second Edition (ADOS-2). It was attempted to categorize the questions into four fields: (1) social interaction, (2) social communication and speech, (3) limited interest pattern with stereotypical and ritualistic behaviors, and (4) comorbidities, etiological characteristics, and the relationship between vaccinations and autism. The results of the study indicate that the awareness of ASD, including core symptoms, was extremely lacking in preschool teachers and school counselors. Moreover, they had extreme prejudice to information known to be incorrect.

\section{Introduction}

The prevalence of autism spectrum disorder (ASD) has shown an increase in the past 10 years in the United States and is now seen predominantly as a plateau, and the increases in prevalence to date can be explained by a great development in awareness and the inclusion in records of milder cases who remain healthy with no mental disability. ${ }^{1-3}$ According to the data of the Centers for Disease Control and Prevention in the United States, ASD prevalence has been reported as 1 in $59 .{ }^{4}$ The increase in ASD prevalence can be seen throughout the world, and this has brought about significant problems with respect to the economies of countries and rehabilitation. The increase in global prevalence is in parallel with the data of the United States.

received

September 6, 2020

accepted after revision

October 29, 2020
DOI https://doi.org/ $10.1055 / \mathrm{s}-0040-1721514$. ISSN 2474-5871.
In recent years, professional training programs for awareness of autism have been supported in the context of health development under the leadership of the United Nations. ${ }^{5}$ In this context, similar awareness studies have been conducted in European Union countries. ${ }^{6}$ ASD is a disorder seen at an increasing frequency in society. It has been attempted to increase autism awareness with strategic action plans, ${ }^{7}$ and action plans directed at autism awareness have started to be implemented in Turkey. ${ }^{8}$ The World Health Organization has emphasized the need to raise the awareness of those providing services to individuals with ASD. ${ }^{9}$

ASD is a neurodevelopmental disorder characterized by deficiencies in social communication and interaction, limited, repeated behaviors, and a limited interest pattern. It manifests with clinical findings with varying symptoms and loss of

\section{(c) 2020. The Author(s).}

This is an open access article published by Thieme under the terms of the Creative Commons Attribution License, permitting unrestricted use, distribution, and reproduction so long as the original work is properly cited. (https://creativecommons.org/licenses/by/4.0/) Georg Thieme Verlag KG, Rüdigerstraße 14, 70469 Stuttgart, Germany 
functions. In the Diagnostic and Statistical Manual of Mental Disorders, Fifth Edition (DSM-5), it has been seen to be appropriate to deal with ASD, which has a wide spectrum of mild, moderate, and severe severity, as a single disorder, and thus the specificity of diagnosis has been increased. ${ }^{10}$ Following the publication of the DSM-5, clinical, legal, and educational regulations related to the new diagnostic criteria for ASD gained pace in the country in general and in relevant institutions, both in Turkey and throughout the world. ${ }^{11}$ Another issue that should be considered is that ASD's recovery rates increase over time with early diagnosis and support. ${ }^{12}$

According to the DSM-5, instead of clinicians determining differences between separate diagnostic categories within a common developmental disorder, an individual can be placed more reliably within an autism spectrum diagnosis, and the severity of the status of the individual can be more easily determined. It has been shown that a more accurate approach is needed for ASD to be considered as a broad spectrum, with symptoms ranging from mild to severe, representing a continuity. ${ }^{13-15}$

Despite these changes in the global sense related to ASD, it can be considered that developing countries such as Turkey have partially lagged behind in capturing awareness of scientific advances of those in contact with ASD individuals and other professionals in the field (preschool teachers, school counselors, and special education, and rehabilitation teachers). The reason for this can be attributed to the training given to teachers, which is only theoretical training, or that changes are not followed up after training. ${ }^{16}$ While aiming to create societal awareness of ASD, it can also be considered important to prioritize training for teachers. For the early application of multidisciplinary treatment, early diagnosis is necessary, and this will certainly change and improve the treatment and rehabilitation process. ${ }^{17}$ It will create a combination that reduces social stigma, which is a huge problem for individuals with ASD and their families, and help with the earlier integration of ASD cases in society. ${ }^{18,19}$

Furthermore, misinformation can cause socially destructive results as that which is incorrect is assumed to be known correctly, but this can be overcome with awareness training. One of the most important examples of this in recent years is the opposition to vaccinations, which is based on the misconception that vaccinations cause autism. ${ }^{20}$

It is especially important in developing countries, such as Turkey, that ASD training seminars are organized, information campaigns should be planned for the public and professionals in the field, and the outcomes of this training should be scientifically evaluated. In an awareness evaluation of nurses trained in the United Kingdom and in South Korea, it was seen that autism awareness campaigns based on truth may not always have an effect on changes in attitude, and this was thought to be due to cultural structure. ${ }^{21}$ Hofstede evaluated cultural differences in six domains defined as closeness/distance, uncertainty/avoidance, individualism/collectivism, masculinity/femininity, long/short-term orientation, and indulgence/restraint. ${ }^{22}$ Several other studies have determined that training increased awareness. ${ }^{7,23,24}$ In the United Kingdom and other countries, it has been aimed to increase autism awareness in a series of legal changes. Most of these measures have been accompanied by significant increases in funding and aid donations. ${ }^{25,26}$

The aim of this study was to determine the knowledge levels and awareness of teachers of ASD according to DSM-5 and to evaluate how training changes this. The secondary aim of the study was that after this training, the teachers in schools would be able to contribute to the appropriate management of this population with recommendations based on scientific data.

\section{Method}

The training was planned in the framework of the protocol signed between Aksaray University and Aksaray Education Authority. With the permission of the governorship, it was planned to organize a training seminar for all 428 participants from preschool teachers and school counselors in Aksaray province together with the Aksaray Provincial Directorate of National Education. A total of 308 teachers were included in the study, comprising 226 preschool teachers and 82 school counselors. Of these, 28 did not wish to participate in the study, but they were given the training. Before applying the questionnaires to the participants, they were given the following information: "The study comprises this questionnaire which measures the awareness and level of knowledge of teachers about autism spectrum disorder. All the information to be used in the study will remain confidential and will only be used for scientific purposes."

Training was delivered to the teachers with interactive participation video support for a total of 4 hours. By providing both theoretical and practical training, the quality of the training given was increased. The training was delivered by a pediatric specialist and a child and adolescent psychiatrist who completed the ASD Screening and Follow-up Program Trainer Training. In our trainings, the materials used by the Ministry of Health in ASD training were used. A 29-item ASD awareness questionnaire was created, which was completed by the participants before and after the training, and thus changes in levels were measured. At the same time, it was aimed for the contributions of the training to be understood. The 29-item questionnaire focusing on ASD awareness was designed to investigate the awareness and knowledge of ASD of professionals in the field. The basic questions were selected according to available publications based on DSM-5 and the Autism Diagnostic Observation Schedule, Second Edition (ADOS-2), which were originally written in English and were then translated into Turkish. ${ }^{13,27}$

\section{Preparation of Questions}

The questions are presented in - Table 1. It was attempted to categorize the questions into four fields: (1) social interaction, such as social relationships, eye contact, common attention, and mimicking ability, (2) social communication and speech, (3) limited interest pattern with stereotypical and ritualistic behaviors, and (4) comorbidities, etiological characteristics, and the relationship between vaccinations and autism. The questions could be answered as yes, no, or I don't know. In one question in field 4 , six alternatives were 
Table 1 The scale applied to teachers to evaluate the level of awareness of autism spectrum disorder

\section{Field 1 \\ Obvious impairment in non-verbal behavior during social contact, such as eye contact, facial expression, posture, is a condition that can be seen in children with autism. \\ A child with autism spectrum disorder cannot develop age-appropriate friendship relationships in school. \\ A child with autism spectrum disorder seems to have no wish to be praised by classmates or teachers, attract interest, or share activities in school. \\ In social and emotional situations, a child with autism spectrum disorder cannot respond emotionally or socially to the other person. \\ Staring into space and not being able to concentrate on a situation compatible with the context are findings often seen in a child with autism spectrum disorder.}

A child with autism spectrum disorder seems to be deaf and mute or likes being alone in class and among friends.

A child with autism spectrum disorder has noticeably reduced interest in their surroundings and the environment.

Children with autism spectrum disorder generally do not have a social smile (when you smile at a child and they smile back at you).

Social communication and interaction has been completely lost in a child with autism spectrum disorder.

A child with autism spectrum disorder can display facial expressions and gestures that will express their feelings comfortably and age-appropriately.

A child with autism spectrum disorder will turn and look consistently when called by name.

A child with autism spectrum disorder tries to attract your attention by pointing to an object or situation that interests them.

When you make a sign to a child with autism spectrum disorder, he/she shares your interest by looking in the direction you have indicated.

A child with autism spectrum disorder can mimic the behavior of other children.

Field 2

Compared with classmates of the same age, there is often delayed speech development or no speech at all.

A child with autism spectrum disorder can develop skills and progress can be recorded as "recovery."

A child with autism spectrum disorder can speak.

\section{Field 3}

They make stereotypical and/or repetitive movements in the classroom, such as flapping the arms like wings, bending the hand or fingers, or making repetitive rhythmic sounds.

Compared with their peers, a child with autism spectrum disorder may show abnormal feeding behavior (e.g., only eating solid or liquid foods, not eating some foods with a different appearance or smell).
Table 1 (Continued)

A child with autism spectrum disorder may always seem to be preoccupied just with the parts of toys or other objects (e.g., focusing on a toy or object not in the form of its function, such as just turning the wheels of a toy car, but not playing with it as a car).

A child with autism spectrum disorder shows extreme and abnormal interest in regular and routine activities around them (e.g., staring at rotating objects, continuously ringing a bell, going to school by the same route, experiencing abnormal discomfort or abnormal interest in senses such as certain sounds, lights, smells, touch and taste).

Field 4

Autism spectrum disorder is childhood schizophrenia.

Autism spectrum disorder is a condition triggered by spontaneous activation of the immune system.

Autism spectrum disorder is a disease associated with structural and functional disorders of the brain.

Autism spectrum disorder is often accompanied by mental retardation in children.

Epilepsy is more common in children with autism spectrum disorder.

The onset of autism spectrum disorder is generally at what age?

While the development is normal in autism spectrum disorder, can symptoms appear later?

The thimerosal substance in vaccines increases the frequency of autism spectrum disorder

given for the age of onset of autism: (1) 0 to 1 month, (2) 1 to 6 months, (3) 6 months to 1 year, (4) 1 to 12 years, (5) 2 to 3 years, and (6) 3 years and older. No open-ended questions were included in the questionnaire.

Mental disability and epilepsy, which may be comorbid with autism, were evaluated with the items, "Autism spectrum disorder is more often accompanied by mental retardation in children" and "Epilepsy is more common in children with autism spectrum disorder." 28

The items in field 1 were prepared with the aim of measuring whether or not social interaction skills can be evaluated qualitatively and quantitatively. The social smile, which is in the ADOS modules, is an important parameter. ${ }^{29}$ A social smile is defined as the child responding with a smile to a smile given in a social context. For teachers to be aware of this and to be able to understand the evaluation, the following item was used, "Children with autism spectrum disorders generally do not have a social smile (when you smile at a child and they smile back at you)."30

"Staring into space and not being able to concentrate on a situation compatible with the context are findings often seen in a child with autism spectrum disorder" aims to determine the ability to be aware that there could be comorbid social attention problems. $^{31}$

"A child with autism spectrum disorder can develop skills and progress can be recorded as recovery" aims to determine if the participants consider autism to be a treatable disorder. ${ }^{32}$ 
"Social communication and interaction has been completely lost in a child with autism spectrum disorder" aims to determine if teachers emphasize impaired quality of social communication. This item was considered necessary to determine the ability to differentiate high functioning ASD cases. ${ }^{33}$

Of the parameters in the ADOS modules, evaluation was made of consistent responses to their name with the item, "A child with autism spectrum disorder will turn and look consistently when called by name," whether the child can spontaneously initiate shared attention with the item, "A child with autism spectrum disorder tries to attract your attention by pointing to an object or situation that interests them," whether they can maintain attention with the item, "When you make a sign to a child with autism spectrum disorder, he shares your interest by looking in the direction you have indicated," whether there are nonverbal communication interaction skills and the use of gestures and facial expressions with the item, "A child with autism spectrum disorder can display facial expressions and gestures that will express their feelings comfortably and age-appropriately" (e. g., waving, blowing a kiss, expressing surprise) and "A child with autism spectrum disorder can mimic the behavior of other children." These items aimed to determine the level of awareness of impairments in social interaction. ${ }^{27}$

The items in field 2 relate to social communication: "Compared with classmates of the same age, there is often delayed speech development or no speech at all" and "A child with autism spectrum disorder can speak."34

The items in field 3 aim to determine the level of awareness of the teachers of limited and repetitive behavior patterns:

- "They make stereotypical and/or repetitive movements in the classroom, such as flapping the arms like wings, bending the hand or fingers, or making repetitive rhythmic sounds."

- "Compared to their peers, a child with autism spectrum disorder may show abnormal feeding behavior (e.g., only eating solid or liquid foods, not eating some foods with a different appearance or smell)."

- "A child with autism spectrum disorder may always seem to be preoccupied just with the parts of toys or other objects (e.g., focusing on a toy or object not in the form of its function, such as just turning the wheels of a toy car, but not playing with it as a car)."

- "A child with autism spectrum disorder shows extreme and abnormal interest in regular and routine activities around them (e.g., staring at rotating objects, continuously ringing a bell, going to school by the same route, experiencing abnormal discomfort or abnormal interest in senses such as certain sounds, lights, smells, touch and taste)."

In field 4, common misconceptions about ASD were questioned. "Autism spectrum disorder is childhood schizophrenia" is a long-held public misconception that leads to stigmatization. That this is incorrect information was included in the training program. The statement that ASD originates from the immune system is unproven information.
Incorrect information is confirmed as proven by unscrupulous individuals providing inappropriate treatments and this has become a market sector. Treatment options such as chelation, intravenous immunoglobulin, hyperbaric oxygen therapy, intranasal oxytocin, gastrointestinal diet, and stem cell treatment are presented as hope for patients. In Turkey in particular, patients often apply for these treatment algorithms. "Autism spectrum disorder is a condition triggered by spontaneous activation of the immune system" raises the question of this information, and this item was included to determine whether teachers have correct information about this subject. ${ }^{35}$

"Autism spectrum disorder is a disorder associated with structural and functional disorders of the brain" aims to determine awareness of the neurostructural and neurochemical bases of the disorder. In the reference of "refrigerator mother" theory, it is emphasized that the disorder is not because of lack of interest from the family. ${ }^{36}$

With the question "The onset of autism spectrum disorder is generally at what age?," it was attempted to determine the awareness of teachers that autism is a disorder with early onset. The discussion of what the early stage red flag symptoms are can be opened from this question as preschool teachers should be alert to this subject. ${ }^{37}$

"While the development is normal in autism spectrum disorder, can symptoms appear later?" was included to determine the level of awareness that symptoms may be encountered during the period known as autistic regression, which is usually linked to another social trauma (sibling rivalry, parental separation, etc.) and delays the age of diagnosis. $^{38}$

The study design and the questionnaire used were approved by the Human Research Ethics Committee of Aksaray University (Number: 2019/12-11).

\section{Statistical Analysis}

Data obtained in the study were analyzed statistically using SPSS 23.0 for Windows software (IBM Corp.; Chicago, Illinois, United States). Conformity of the data to normal distribution was assessed using the Shapiro-Wilk test, and the data were found to be normally distributed. To compare the mean values of a variable in two different conditions, the paired samples $t$ test was used, and to compare the mean of categorical variables between two groups, the chi-square test was applied. A value of $p<0.05$ was accepted as statistically significant.

\section{Results}

The total 308 participants comprised 226 (73.4\%) preschool teachers and 82 (26.6\%) school counselors, of which 262 (85.1\%) were female and 46 (14.9\%) were male. The educational levels of the participants were as follows: 294 (95.5\%) were university graduates, 8 (2.6\%) were further education college graduates, 3 (1\%) had completed high school (12 years of compulsory education), and 3 (1\%) were postgraduates. Of the total participants, $170(55.2 \%)$ worked half-days, 129 (41.9\%) worked full days, and 9 (2.9\%) did not respond to this question. 
Training related to ASD was received during university education by $162(52.6 \%)$ teachers, and $146(47.4 \%)$ reported that they had not received any training. When the professional experience of teaching was examined, 5 teachers (1.6\%) had $<3$ years of experience, $46(14.9 \%)$ had 3 to 6 years of experience, 74 (24\%) had 6 to 9 years of experience, 144 (46.8\%) had 10 to 20 years of experience, and 39 (12.7\%) had $>20$ years of experience. Within the scope of professional experience, having encountered a child with ASD was reported by 150 (48.7\%) teachers, and 158 (51.3\%) stated that they had not. Following the training, 251 (81.5\%) teachers stated that if they identified a child with ASD symptoms, they would refer the child to a doctor, and 57 (18.5\%) stated that they would not make such a referral.

The responses to the questionnaire given by the teachers before the training session were compared according to gender. To the field 1 item of "Staring into space and not being able to concentrate on a situation compatible with the context are findings often seen in a child with autism spectrum disorder," a response of "Yes" was given by 254/ 262 female teachers (96.9\%) and 39/46 male teachers (84.8\%) $(p=0.001)$. To the field 2 item "A child with autism spectrum disorder can speak," a response of "Yes" was given by 256 (97.7\%) females and $42(91.3 \%)$ males and "No" by $6(2.3 \%)$ females and $4(8.7 \%)$ males $(p=0.024)$.

When the responses were examined according to the type of teaching, the field 4 item "Autism spectrum disorder is often accompanied by mental retardation in children" was answered with "I don't know" by $7.1 \%(n=16)$, "Yes" by $64.6 \%$ $(n=146)$, and "No" by $28.3 \%(n=64)$ of the preschool teachers, and these rates were $1.2 \%(n=1), 82.9 \%(n=68)$, and $15.9 \%(n=13)$ for the school counselors, respectively $(p=0.06)$. The item in Field 4 of "Epilepsy is more common in children with autism spectrum disorder" was answered with "I don't know" by $8.4 \%(n=19)$, "Yes" by $77 \%(n=174)$ and "No" by $14.6 \%(n=33)$ of the preschool teachers, and the response was "Yes" by $90.2 \%(n=74)$, and "No" by $9.8 \%$ $(n=8)$ of the school counselors $(p=0.010)$.

When the age factor of the respondents was considered, to the Field 1 item of "Social communication and interaction has been completely lost in a child with autism spectrum disorder," all the teachers aged $<25$ years $(n=2,100 \%)$ responded "No"; of the 72 teachers aged 25 to 30 years, 18 (25\%) responded "Yes" and 54 (75\%) responded "No"; of the 96 teachers aged 30 to 35 years, $6(6.3 \%)$ replied "I don't know," 20 (20.8\%) replied "Yes," and 70 (72.9\%) replied "No"; of the 76 teachers aged 35 to 40 years, 27 (35.5\%) responded "Yes" and $49(64.5 \%)$ responded "No"; of the 62 teachers aged $>40$ years, 2 (3.2\%) replied "I don't know," 25 (40.3\%) replied "Yes," and 35 (56.5\%) replied "No" ( $p=0.018)$. No significant results were determined in other parameters when examined according to the age of the teachers.

When the responses were compared according to the professional experience of the respondents, for the item "A child with autism spectrum disorder has noticeably reduced interest in their surroundings and the environment," which emphasizes the absence of social interaction, a response of "Yes" was given by $4(80 \%)$ of 5 teachers with $<3$ years of experience, 141 (97.9\%) teachers with 10 to 20 years of experience, and 38 (97.4\%) of those with more than 20 years of experience $(p=0.032)$. The item "A child with autism spectrum disorder may always seem to be preoccupied just with the parts of toys or other objects," which refers to stereotypical behavior, was given the response of "Yes" by 4 (80\%) teachers with $<3$ years of experience, 142 (98.6\%) teachers with 10 to 20 years of experience, and 37 (94.9\%) of those with more than 20 years of experience $(p=0.001)$

\section{(-Table 2).}

When teachers who had and had not previously encountered a child with ASD in their professional teaching life were compared, to the item of "Autism spectrum disorder is more often accompanied by mental retardation in children," a response of "Yes" was given by 116/150 (77.3\%) teachers who had previously encountered a child with ASD and by $98 /$ $158(62 \%)$ of those who had not, and the difference was statistically significant $(p=0.012)$. To the field 4 item of "Epilepsy is more common in children with autism spectrum disorder," a response of "Yes" was given by 128/150 (85.3\%) teachers who had previously encountered a child with ASD and by $120 / 158(75.9 \%)$ of those who had not $(p=0.010)$ (-Table 3).

When the relationship was examined between having received ASD education at a university and feeling able to refer a child with suspected ASD to a physician, after the training in this study, 145/162 (89.5\%) teachers who had received training at university stated that they would be able to make such a referral and 105/145 (72.4\%) of those who had not received training at university stated that they would be able to, and the difference was statistically significant $(p=0.001)$. After the training in this study, 134/150 (89.3\%) teachers who had previously encountered a child with ASD and 117/158 (74.1\%) of those who had not previously encountered a child with ASD stated that they would be able to refer a child with suspected ASD to a physician, and the difference was statistically significant $(p=0.001)$.

When the questionnaires applied before and after the ASD training were evaluated within the teacher groups, it was seen that for the preschool teachers, there was a statistically significant improvement in correct responses to all the items in fields 2,3 , and 4 , and, with the exception of items $1,2,4$, and 6 , to the other items in field 1 . For the school counselors, with the exceptions of items 4 and 6 in field 4, there was determined to be a statistically significant positive change in the responses to all the other items after the training (-Table 4).

\section{Discussion}

With the advent of the DSM-5 in 2013, conditions that were named widespread developmental disorders in the past started to be evaluated as ASD. ${ }^{10}$ Although DSM- 5 criteria have started to be applied by health care professionals in our province, the evaluations of this study showed that this was not reflected in life. These evaluations suggested that as the professional groups dealing with preschool-aged children in particular either acted on information they had learned 


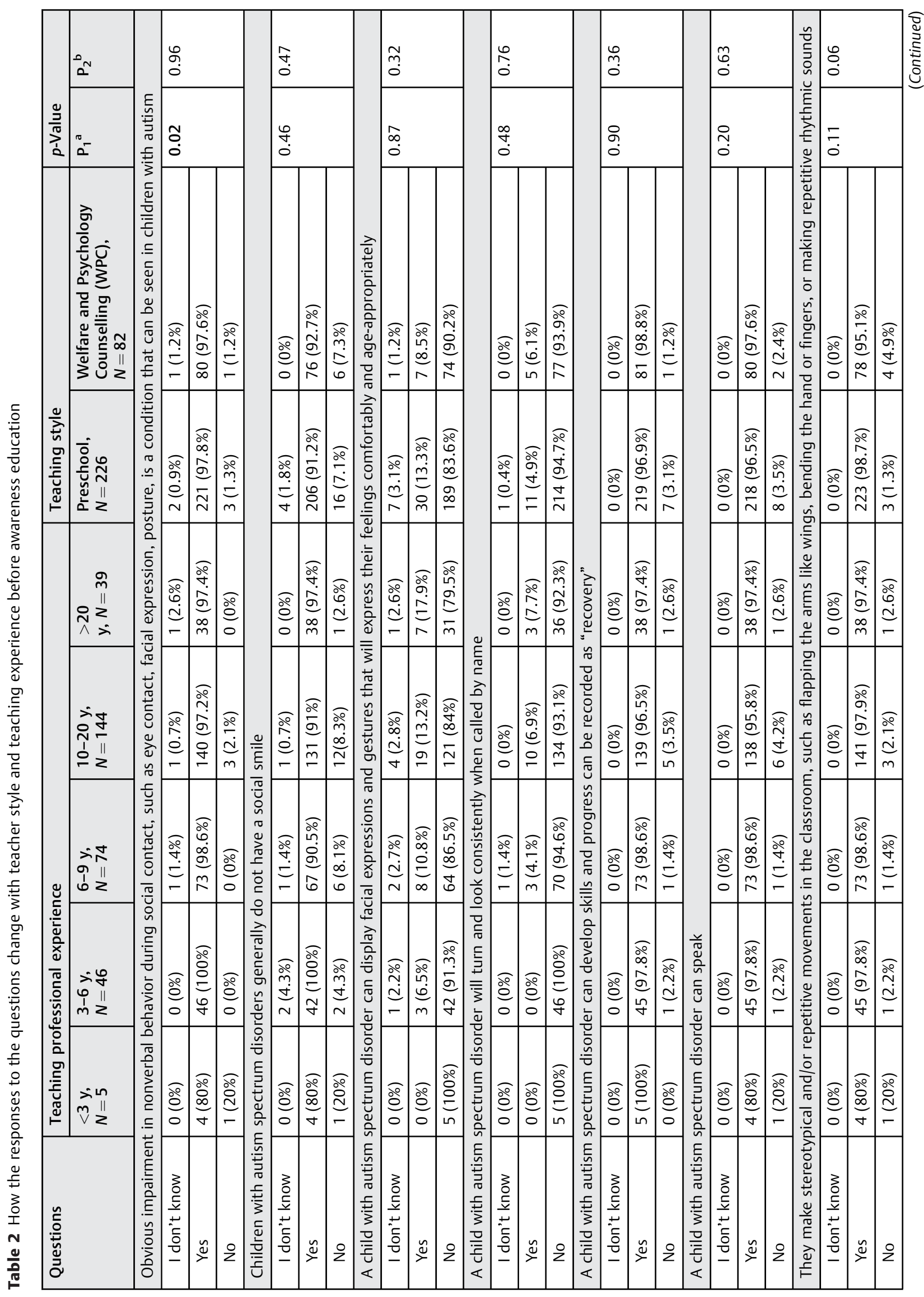




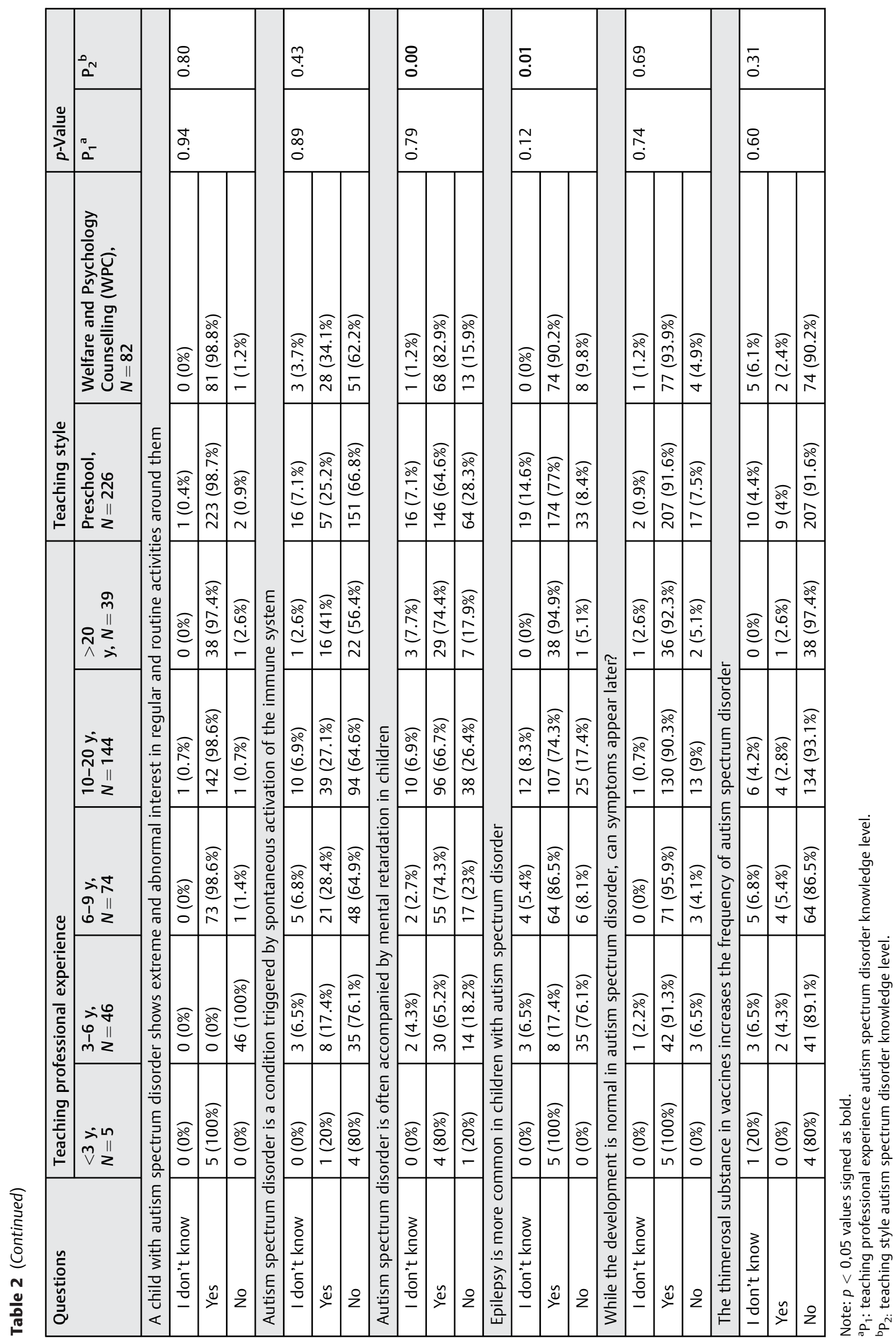


Table 3 Noticing the child with ASD and referring it to the doctor

\begin{tabular}{|c|c|c|c|}
\hline & \multicolumn{2}{|c|}{$\begin{array}{l}\text { To be able to recognize a } \\
\text { child with autism spectrum } \\
\text { disorder after the education } \\
\text { and direct it to the doctor }\end{array}$} & \multirow[t]{2}{*}{$p$-Value } \\
\hline & Yes & No & \\
\hline \multicolumn{4}{|c|}{$\begin{array}{l}\text { To meet a child with autism spectrum disorders around or } \\
\text { between relatives }\end{array}$} \\
\hline Yes & $134(89.3 \%)$ & $16(10.7 \%)$ & \multirow[t]{2}{*}{0.001} \\
\hline No & 117 (74.1\%) & 41 (25.9\%) & \\
\hline \multicolumn{4}{|c|}{$\begin{array}{l}\text { Take educating in university years related to autism } \\
\text { spectrum disorder }\end{array}$} \\
\hline Yes & $145(89.5 \%)$ & 17 (10.5\%) & \multirow[t]{2}{*}{0.001} \\
\hline No & 105 (72.4\%) & $40(27.6 \%)$ & \\
\hline
\end{tabular}

previously or did not have sufficient information, there were deficiencies in the diagnostic process of children with suspected ASD and the accurate referral to health care institutions. As the majority of the teachers in this study had received autism training while at university and there had been insufficient training seminars in the period of their professional work, the lack of information continued throughout the professional experience.

Of the total study participants, $47.7 \%$ reported that they had received no training about ASD during higher education and $84.7 \%$ stated that they had not received in-service training related to ASD. This can be considered to be the cause of outdated, stereotyped, and forgotten information related to ASD. ${ }^{7}$ This can even lead to a tendency to practices that can be harmful to children, such as opposition to vaccinations, and there can be a shift to ASD diagnosis at an older age. Subsequently, this can affect disorder prognosis in an extremely negative way. In developing countries such as Turkey and those where the popularity of current thought may be distant from positivism, this situation can be encountered as a severe risk.

Moreover, teachers who have not received appropriate and current training may direct the parents of children with ASD to unproven and harmful treatment methods. This not only prevents the child from receiving appropriate education but also incurs unnecessary costs and loss of workforce for the state.

On examination of the university curricula in Turkey, it can be seen that in the majority, the education period of preschool teachers is shorter than that of school counselors. ${ }^{39,40}$ As there are different lesson programs in each university in Turkey, and lessons are delivered by academicians of different capabilities, it does not seem possible to obtain a standard in teacher training. Of the teachers participating in this study, approximately three-quarters were preschool teachers. Although 95.5\% of all the teachers were educated to graduate level, almost half of these (47.7\%) had received no education about ASD. In-service training about ASD had not been received by $84.7 \%$ of the teachers. After receiving the training in this study, $89.5 \%$ of those who received education about ASD during higher education stat- ed that they could refer a child with suspected ASD to the relevant physician, and $72.4 \%$ of the teachers who had not received education about ASD during higher education believed that they could refer a child.

It is extremely important for the professional groups working with these children that teachers have information about comorbid disorders seen in children with $\mathrm{ASD}^{41}$ because usually a child with ASD is not dealing with a single disorder. ${ }^{42}$ Every symptom may not be due to ASD, or when other disease symptoms are seen, the education applications to be given may show individual differences. ${ }^{42}$ Teachers who had previously worked with a child with ASD stated at the rate of $81.3 \%$ that there could be comorbidities in ASD, whereas this rate for other teachers was $66.9 \%$.

While the gender of the teachers made no difference to the level of awareness of ASD, there was seen to be a difference in respect of whether the respondents were preschool teachers or school counselors. Although it was predicted that there would be no difference related to gender in the identification of ASD, it was evaluated as there are studies related to this. ${ }^{43}$

To the field 4 item of "Autism spectrum disorder is more often accompanied by mental retardation in children," a response of "Yes " was given by $64.6 \%(n=146)$ of the preschool teachers and by $82.9 \%(n=68)$ of the school counselors $(p=0.06)$ Coexistence of severe mental retardation and autism was reported as $32.1 \%$ in a study conducted in Japan. ${ }^{44}$ To the item "Epilepsy is more common in children with autism spectrum disorder," a response of "Yes " was given by $77 \%(n=174)$ of the preschool teachers and by $90.2 \%$ $(n=74)$ of the school counselors $(p=0.010)$. In a study by Lukmanji et al, it was found that the prevalence of epilepsy in autism patients was higher than the normal population. ${ }^{45}$ It can be said that the school counselors had more detailed knowledge following the training about ASD.

In Turkey, school counselors are not usually employed in preschool educational institutions. ${ }^{46}$ However, as it can be predicted that school counselors will have received better education about ASD and neurodevelopmental disorders and, as seen in this study, will have a higher awareness level, the employment of these teachers in preschool education facilities will increase the chance of early intervention for ASD.

When the age factor of all the teachers was considered, to the item of "Social communication and interaction has been completely lost in a child with autism spectrum disorder," which emphasized that there could be poor quality social communication in ASD, a response of "No" was given by all the teachers aged $<25$ years ( $n=2,100 \%), 54$ (75\%) of the 72 teachers aged 25 to 30 years, 70 (72.9\%) of the 96 teachers aged 30 to 35 years, 49 (64.5\%) of the 76 teachers aged 35 to 40 years, and 35 (56.5\%) of the 62 teachers aged $>40$ years, and these results were found to be statistically significant $(p=0.018)$. In a meta-analysis by Fuller and Kaiser, they emphasized the importance of early recognition of the poor quality of social communication in autism. ${ }^{47}$ Younger teachers were seen to give more importance to the field of social communication and interaction. Therefore, it is more important that the knowledge of older teachers is updated. It can be 
e254 Awareness of Autism Spectrum Disorder among Turkısh Teachers Kara, Demirtaş

Table 4 The relationship of the responses of the participants with the survey questions before and after the practice

\begin{tabular}{|c|c|c|c|c|c|c|c|}
\hline & \multicolumn{2}{|c|}{$\begin{array}{l}\text { 95\% confidence interval } \\
\text { of the difference }\end{array}$} & \multirow[t]{2}{*}{$p$-Value } & & \multicolumn{2}{|c|}{$\begin{array}{l}\text { 95\% confidence interval } \\
\text { of the difference }\end{array}$} & \multirow[t]{2}{*}{$p$-Value } \\
\hline & Lower & Upper & & & Lower & Upper & \\
\hline \multicolumn{4}{|l|}{ Field 1/Q1 } & \multicolumn{4}{|l|}{ Field 2/Q1 } \\
\hline Preschool & -0.0673 & 0.1429 & 0.202 & Preschool & -0.2021 & -0.5454 & 0.001 \\
\hline WPC & -0.1241 & 0.0021 & 0.058 & WPC & -0.3999 & 0.5950 & 0.697 \\
\hline \multicolumn{4}{|l|}{ Field $1 / \mathrm{Q} 2$} & \multicolumn{4}{|l|}{ Field 2/Q2 } \\
\hline Preschool & -0.1005 & 0.1209 & 0.123 & Preschool & -0.1485 & -0.0638 & 0.001 \\
\hline WPC & -0.0853 & 0.0610 & 0.741 & WPC & -0.1307 & -0.1560 & 0.013 \\
\hline \multicolumn{4}{|l|}{ Field $1 / \mathrm{Q} 3$} & \multicolumn{4}{|c|}{ Welfare and Psychology Counselling (WPC) } \\
\hline Preschool & -0.2565 & -0.974 & 0.001 & Preschool & -0.1173 & -0.4199 & 0.001 \\
\hline WPC & -0.1916 & 0.4533 & 0.223 & Adviser & -0.3079 & 0.6737 & 0.461 \\
\hline \multicolumn{4}{|l|}{ Field $1 / \mathrm{Q} 4$} & \multicolumn{4}{|l|}{ Field 3/Q1 } \\
\hline Preschool & -0.9142 & 0.0471 & 0.530 & Preschool & -0.1871 & -0.0871 & 0.001 \\
\hline WPC & -0.1014 & 0.5262 & 0.530 & WPC & -0.2317 & -0.0609 & 0.001 \\
\hline \multicolumn{4}{|l|}{ Field $1 / \mathrm{Q} 5$} & \multicolumn{4}{|l|}{ Field 3/Q2 } \\
\hline Preschool & -0.4335 & -0.0787 & 0.007 & Preschool & -0.3963 & -0.2230 & 0.001 \\
\hline WPC & -0.2392 & -0.0777 & 0.001 & WPC & -0.3082 & -0.0578 & 0.005 \\
\hline \multicolumn{4}{|l|}{ Field 1/Q6 } & \multicolumn{4}{|l|}{ Field 3/Q3 } \\
\hline Preschool & -0.2137 & 0.0013 & 0.053 & Preschool & -0.1971 & -0.0949 & 0.001 \\
\hline WPC & -0.1988 & 0.0037 & 0.059 & WPC & -0.1793 & -0.1579 & 0.20 \\
\hline \multicolumn{4}{|l|}{ Field $1 / \mathrm{Q} 7$} & \multicolumn{4}{|l|}{ Field 3/Q4 } \\
\hline Preschool & -0.1871 & -0.6952 & 0.001 & Preschool & -0.1586 & -0.0625 & 0.001 \\
\hline Adviser & -0.1694 & 0.0231 & 0.134 & WPC & -0.1486 & -0.0023 & 0.057 \\
\hline \multicolumn{4}{|l|}{ Field $1 / \mathrm{Q} 8$} & \multicolumn{4}{|l|}{ Field 4/Q1 } \\
\hline Preschool & -0.2526 & -0.0835 & 0.001 & Preschool & -0.7983 & -0.5379 & 0.001 \\
\hline WPC & -0.3392 & -0.0997 & 0.001 & WPC & -0.5343 & -0.1485 & 0.001 \\
\hline \multicolumn{4}{|l|}{ Field 1/Q9 } & \multicolumn{4}{|l|}{ Field 4/Q2 } \\
\hline Preschool & -0.3784 & -0.1259 & 0.001 & Preschool & -1.542 & -0.7761 & 0.001 \\
\hline WPC & -0.2037 & 0.1549 & 0.787 & WPC & -0.8369 & -0.4313 & 0.001 \\
\hline Field $1 / \mathrm{Q} 1$ & & & & Field $4 / Q_{3}$ & & & \\
\hline Preschool & -0.6287 & -0.3800 & 0.001 & Preschool & -0.3036 & -0.1388 & 0.001 \\
\hline WPC & -0.4489 & -0.1364 & 0.001 & WPC & -0.3119 & -0.0783 & 0.001 \\
\hline Field $1 / \mathrm{Q} 1$ & & & & Field $4 / \mathrm{Q} 4$ & & & \\
\hline Preschool & -0.8711 & -0.6421 & 0.001 & Preschool & -0.4071 & -0.1327 & 0.001 \\
\hline WPC & -0.7286 & -0.3688 & 0.001 & WPC & -0.1105 & 0.2812 & 0.389 \\
\hline Field $1 / \mathrm{Q} 1$ & & & & Field $4 / Q 5$ & & & \\
\hline Preschool & -1.006 & -0.7727 & 0.001 & Preschool & -0.5621 & -0.3316 & 0.001 \\
\hline WPC & -0.9486 & -0.5879 & 0.001 & WPC & -0.4894 & -0.0958 & 0.004 \\
\hline Field $1 / \mathrm{Q} 1$ & & & & Field 4/Q6 & & & \\
\hline Preschool & -0.8206 & -0.5775 & 0.001 & Preschool & 0.2470 & 0.7264 & 0.001 \\
\hline WPC & -0.9145 & -0.5488 & 0.001 & WPC & -0.1550 & 0.6672 & 0.219 \\
\hline Field $1 / \mathrm{Q} 1$ & & & & Field 4/Q7 & & & \\
\hline Preschool & -0.0659 & -0.9086 & 0.001 & Preschool & -1.211 & -1.018 & 0.001 \\
\hline WPC & -0.9303 & -0.5087 & 0.001 & WPC & -1.210 & -0.8385 & 0.001 \\
\hline & & & & Field 4/Q8 & & & \\
\hline & & & & Preschool & -1.597 & -1.376 & 0.001 \\
\hline & & & & WPC & -1.466 & -1.069 & 0.001 \\
\hline
\end{tabular}


understood from these data that the opinions of ASD of the older teachers were less compatible with DSM-5, but as the DSM-5 was published in 2013, this difference between the age groups is not surprising because when the older teachers completed their further education, the DSM-5 had not been introduced.

Similarly, when professional experience was examined, it was seen that the more experienced teachers better evaluated the quantitative characteristics. For the item "A child with autism spectrum disorder has noticeably reduced interest in their surroundings and the environment," which emphasizes the absence of social interaction, a response of "Yes" was given by $80 \%$ of teachers with $<3$ years of experience, $97.9 \%$ of teachers with 10 to 20 years of experience, and $97.4 \%$ of those with more than 20 years of experience Children with ASD show atypical social behavior but vary in their social interaction style (SIS), ranging from social aloofness to awkward social approaches. Being able to understand the changes in this SIS may be related to professional experience. ${ }^{48}$ When discussed together with the information in the previous paragraph, it can be said that although experienced teachers know better that there is reduced social interest, they do not evaluate this reduction qualitatively but tend to evaluate it quantitatively as present or absent.

The item "A child with autism spectrum disorder may always seem to be preoccupied just with the parts of toys or other objects," which refers to stereotypical behavior, was given the response of "Yes" by $80 \%$ of teachers with $<3$ years of experience, $98.6 \%$ of teachers with 10 to 20 years of experience, and $94.9 \%$ of those with more than 20 years of experience $(p=0.001) .{ }^{49}$ However much it is aimed to increase awareness of ASD with training given to teachers, this will not replace the experience gained working with children; therefore, it is essential that there is a practical element to the training given.

Following the training, there was a statistically significant increase in the level of knowledge and awareness of all the teachers with respect to the items in field $3 .^{50,51}$ Other awareness studies have also reported similar positive differences in pre- and posttraining values for training given about stereotypical and repetitive movements. ${ }^{7,24}$

With the spread of incorrect information, there has been a recent increasing trend for opposition to vaccinations, and this has started to become a serious public health problem. ${ }^{52}$ Families are hesitant to have their child vaccinated with the concern that it could lead to ASD, and thus the children remain unvaccinated. ${ }^{53}$ It is a common belief that the thimerosal substance, which is a preservative in the vaccination, can constitute a risk for ASD. ${ }^{54}$ The item "The thimerosal substance in vaccines increases the frequency of autism spectrum disorder" was asked with the aim of raising awareness of this subject. It was seen that a significant proportion of the preschool teachers had concerns that vaccinations can lead to ASD. However, after the training, it was statistically significantly shown that these prejudices had clearly changed. Before the training, only $18.2 \%$ of the teachers indicated that vaccinations would not cause ASD, and this rate increased to $91.6 \%$ after the training. Before the training, $74 \%$ of the teachers indicated that they did not know whether or not vaccinations would cause autism. Thus, it can be seen that in the spread of community-based correct information, training and education are extremely important. ${ }^{55-58}$

When it is considered that ASD can be seen in 1 in 59 children, the response that only $48.7 \%$ of the teachers had encountered a child with ASD in their professional life shows lack of awareness of the disorder. ${ }^{4}$ As $83.5 \%$ of the teachers had more than 6 years of professional experience, this means that the vast majority undertook their higher education before the introduction of the DSM-5. Therefore, they tended to view the disorder cross-sectionally rather than as a spectrum. As there has been no updating of education, there is a great deficiency in awareness. Nevertheless, the teachers wished to receive training and were highly motivated. Before the training given in this study, $81.5 \%$ of the participants believed that on completion they would be able to identify and manage ASD and after the training, and this rate increased to $92.7 \%(p=0.024)$.

As in similar awareness studies, in this multidisciplinary field study, significant positive changes were determined after training compared with the pretraining values in all the fields of social interaction, social communication, stereotypical behavior and repetitive movements and general knowledge of autism and public misconceptions. ${ }^{7,23,24,59-61}$

\section{Limitations}

The single-center nature of our study is a disadvantage. It seems appropriate to compile data with multicenter studies. Trainings for teachers need to be more standardized. In addition, practical training is needed more for the awareness changes in teachers. Cultural differences may be important in awareness training. When advances are made in the cultural dimensions described by Hofstede, the training will be more useful, ${ }^{22}$ and when this training is applied, it will contribute to cultural advances.

\section{Conclusion}

From the results of this study, it can be said that there are serious deficiencies in the knowledge and awareness of ASD, including the core symptoms, of preschool teachers and school counselors in Turkey. They also have serious prejudice for information which is known to be incorrect. It must not be forgotten that this can lead to a serious public health problem in developing countries such as Turkey.

Thus, it can be concluded that for teachers to be encouraged on the subject of referring children with suspected ASD to health care institutions, there is a need for school counselors to be employed in preschool education facilities, there is a need for the revision of training about neurodevelopmental disorders, primarily ASD, which is given as part of the further education of both preschool teachers and school counselors, and there is a need for regular in-service teacher training within the institutions on the subject of ASD to be given by pediatricians and pediatric psychiatrists.

In addition to theoretical training, practical and/or videosupported training for teachers is extremely important for the identification of the disorder. Differences were 
determined between teachers who had previously seen or not seen a child with ASD with respect to recognizing the disorder and referring the child to a child and adolescent psychiatrist. Therefore, bringing experienced and inexperienced teachers together is important to be able to increase knowledge-sharing environments.

Conflict of Interest

None declared.

\section{References}

1 Demirkaya SK. Otizm neden artışta? Klinik Psikiyatri. 2019; 22:123-124

2 Ercan ES, Motavallı NE. Otizm spektrum bozukluklarında tanım, prevalans ve klinik özellikler. Nörogelişimsel Bozukluklar: İstanbul, Nobel Yayınevi; 2018:261-284

3 King M, Bearman P. Diagnostic change and the increased prevalence of autism. Int J Epidemiol 2009;38(05):1224-1234

4 Baio J, Wiggins L, Christensen DL, et al. Prevalence of autism spectrum disorder among children aged 8 years-autism and developmental disabilities monitoring network, 11 sites, United States, 2014. MMWR Surveill Summ 2018;67(06):1-23

5 Posar A, Visconti P. Long-term outcome of autism spectrum disorder. Turk Pediatri Ars 2019;54(04):207-212

6 United Nations World Autism Awareness Day. Available at: https://www.un.org/en/events/autismday/index.shtml. Access Date: 30 August 2020

7 Giannopoulou I, Pasalari E, Korkoliakou P, et al. Raising autism awareness among Greek teachers. Int J Disabil Dev Educ 2019;66 (01):70-81

8 Department of Health Fulfilling and rewarding lives: the strategy for adults with autism in England. Available at: https://www.gov. uk/government/news/fulfilling-and-rewarding-lives-the-strategy-for-adults-with-autism-in-england. Accessed 28 August 2020

9 Turkey MoFaSPo National Action Plan for Individuals with Autism Spectrum Disorder (2016-2019). 2016. Available at: https:// www.resmigazete.gov.tr/eskiler/2016/12/20161203-16.htm.

Accessed 26 August 2020

10 American Psychiatric Association Diagnostic and Statistical Manual of Mental Disorders, Fifth Edition (DSM-5). Philadelphia, PA: American Psychiatric Association; 2013

11 Turkey MoFaSPo Autism E- Newsletter Special Issue. 2019. Access Date: 26 August 2020

12 World Health Organization Autism spectrum disorders \& other developmental disorders: from raising awareness to building capacity. Available at: https://apps.who.int/iris/bitstream/handle/10665/103312/9789241506618_eng.pdf;jsessionid=7EDC04C1AB7E6F8E4D7BFBB9A5F533FA? sequence $=1$. Accessed 26 August 2020

13 Grant R, Nozyce M. Proposed changes to the American Psychiatric Association diagnostic criteria for autism spectrum disorder: implications for young children and their families. Matern Child Health J 2013;17(04):586-592

14 Kurita H. How to deal with the transition from Pervasive Developmental Disorders in DSM-IV to Autism Spectrum Disorder in DSM-V. Psychiatry Clin Neurosci 2011;65(07):609-610

15 Brugha TS, McManus S, Bankart J, et al. Epidemiology of autism spectrum disorders in adults in the community in England. Arch Gen Psychiatry 2011;68(05):459-465

16 Al-Mamri W, Idris AB, Dakak S, et al. Revisiting the prevalence of Autism spectrum disorder among Omani children: a multicentre study. Sultan Qaboos Univ Med J 2019;19(04):e305-e309

17 Brignell A, Morgan AT, Woolfenden S, et al. A systematic review and meta-analysis of the prognosis of language outcomes for individuals with autism spectrum disorder. Autism \& Developmental Language Impairments. 2018;3:2396941518767610
18 Franz L, Dawson G. Implementing early intervention for autism spectrum disorder: a global perspective. Pediatr Med 2019;2(44):

19 Stronach S, Wiegand S, Mentz E. Brief report: Autism knowledge and stigma in university and community samples. J Autism Dev Disord 2019;49(03):1298-1302

20 Hviid A, Stellfeld M, Wohlfahrt J, Melbye M. Association between thimerosal-containing vaccine and autism. JAMA 2003;290(13): 1763-1766

21 Mac Cárthaigh S, López B. Factually based autism awareness campaigns may not always be effective in changing attitudes towards autism: Evidence from British and South Korean nursing students. Autism 2020;24(05):1177-1190

22 Hofstede G. Dimensionalizing cultures: the Hofstede model in context. Online Read Psychol Cult 2011;2(01):8

23 Kelly E, Hassett-Walker C. The training of New Jersey emergency service first responders in autism awareness. Police Pract Res 2016;17(06):543-554

24 Ashworth S, Tully RJ. Autism awareness training for youth offending team staff members. Advances in Autism 2017;3(04):240-249. Available at: https://doi.org/10.1108/AIA-04-2017-0010

25 Autism Spectrum Disorder Bill. 2017. Available at: https://www. oireachtas.ie/en/bills/bill/2017/61/. Acces Date: 26 August 2020

26 Government of UK Autism Act. 2009. Available at: http://www. legislation.gov.uk/ukpga/2009/15. Access Date: 26 August 2020

27 Lord C, Rutter M, DiLavore P, et al. Autism Diagnostic Observation Schedule, (ADOS-2, Modules 1-4). Los Angeles, CA: Western Psychological Services; 2012

28 Matson JL, Nebel-Schwalm MS. Comorbid psychopathology with autism spectrum disorder in children: an overview. Res Dev Disabil 2007;28(04):341-352

29 Lord C, Risi S, Lambrecht L, et al. The autism diagnostic observation schedule-generic: a standard measure of social and communication deficits associated with the spectrum of autism. J Autism Dev Disord 2000;30(03):205-223

30 Ozonoff S, Iosif AM, Baguio F, et al. A prospective study of the emergence of early behavioral signs of autism. J Am Acad Child Adolesc Psychiatry 2010;49(03):256-66.e1, 2

31 Dawson G, Toth K, Abbott R, et al. Early social attention impairments in autism: social orienting, joint attention, and attention to distress. Dev Psychol 2004;40(02):271-283

32 Fernell E, Eriksson MA, Gillberg C. Early diagnosis of autism and impact on prognosis: a narrative review. Clin Epidemiol 2013;5:33-43

33 Locke J, Ishijima EH, Kasari C, et al. Loneliness, friendship quality and the social networks of adolescents with high-functioning autism in an inclusive school setting. J Res Spec Educ Needs 2010; 10(02):74-81

34 Goldstein H. Communication intervention for children with autism: a review of treatment efficacy. J Autism Dev Disord 2002;32 (05):373-396

35 Medavarapu S, Marella LL, Sangem A, Kairam R. Where is the evidence? A narrative literature review of the treatment modalities for autism spectrum disorders. Cureus 2019;11(01):e3901

36 Kanner L. Autistic disturbances of affective contact. Nerv Child 1943;2(03):217-250

37 Dow D, Day TN, Kutta TJ, Nottke C, Wetherby AM. Screening for autism spectrum disorder in a naturalistic home setting using the systematic observation of red flags (SORF) at 18-24 months. Autism Res 2020;13(01):122-133

38 Boterberg S, Charman T, Marschik PB, Bölte S, Roeyers H. Regression in autism spectrum disorder: A critical overview of retrospective findings and recommendations for future research. Neurosci Biobehav Rev. 2019Jul102:24-55

39 Marmara University Basic education department ptpcc. Available at: http://okl.aef.marmara.edu.tr/lisans-programi/ders-icerikleri. Accessed 29 August 2020

40 Marmara University Curriculum GaPCUPM. Available at: http:// pdr.aef.marmara.edu.tr/lisans-programi. Access Date: 29 August 2020 
41 Simonoff E, Pickles A, Charman T, Chandler S, Loucas T, Baird G. Psychiatric disorders in children with autism spectrum disorders: prevalence, comorbidity, and associated factors in a population-derived sample. J Am Acad Child Adolesc Psychiatry 2008;47(08):921-929

42 Eldevik S, Eikeseth S, Jahr E, Smith T. Effects of low-intensity behavioral treatment for children with autism and mental retardation. J Autism Dev Disord 2006;36(02):211-224

43 Baron-Cohen $S$. The extreme male brain theory of autism. Trends Cogn Sci 2002;6(06):248-254

44 Nomura K, Yamaguchi M, Yokoyama M, Shiota M, Ohno K, Maegaki Y. A study on the incidence and comorbidities of autism spectrum disorders accompanied by intellectual disabilities in Yonago City, Japan. Yonago Acta Med 2019;62(01):8-13

45 Lukmanji S, Manji SA, Kadhim S, et al. The co-occurrence of epilepsy and autism: a systematic review. Epilepsy Behav 2019; 98(Pt A)238-248

46 Aydın A, Sarıer Y, Uysal Ş, et al. Türkiye'de öğretmen istihdamı politikalarının değerlendirilmesi. Kuram ve Uygulamada Egitim Yönetimi Dergisi 2014;20(04):397-420

47 Fuller EA, Kaiser AP. The effects of early intervention on social communication outcomes for children with autism spectrum disorder: a meta-analysis. J Autism Dev Disord 2020;50(05):1683-1700

48 Scheeren AM, Koot HM, Begeer S. Stability and change in social interaction style of children with autism spectrum disorder: a 4year follow-up study. Autism Res 2020;13(01):74-81

49 Carcani-Rathwell I, Rabe-Hasketh S, Santosh PJ. Repetitive and stereotyped behaviours in pervasive developmental disorders. J Child Psychol Psychiatry 2006;47(06):573-581

50 Zachor DA, Ben-Itzchak E. The relationship between clinical presentation and unusual sensory interests in autism spectrum disorders: a preliminary investigation. J Autism Dev Disord 2013; 44(01):229-235
51 Gabriels RL, Agnew JA, Miller LJ, et al. Is there a relationship between restricted, repetitive, stereotyped behaviors and interests and abnormal sensory response in children with autism spectrum disorders? Res Autism Spectr Disord 2008;2(04):660-670

52 Dixon GN, Clarke CE. Heightening uncertainty around certain science: Media coverage, false balance, and the autism-vaccine controversy. Sci Commun 2013;35(03):358-382

53 Smith MJ, Ellenberg SS, Bell LM, Rubin DM. Media coverage of the measles-mumps-rubella vaccine and autism controversy and its relationship to MMR immunization rates in the United States. Pediatrics 2008;121(04):e836-e843

54 Offit PA. Thimerosal and vaccines-a cautionary tale. N Engl J Med 2007;357(13):1278-1279

55 Fombonne E. Epidemiological controversies in autism. Swiss Arch Neurology Psychiatry Psychotherapy 2020;171(01):

56 Fombonne E, Goin-Kochel RP, O'Roak BJSPARK Consortium. Beliefs in vaccine as causes of autism among SPARK cohort caregivers. Vaccine 2020;38(07):1794-1803

57 DeStefano F, Shimabukuro TT. The MMR vaccine and autism. Annu Rev Virol 2019;6(01):585-600

58 Deer B. Secrets of the MMR scare. How the vaccine crisis was meant to make money. BMJ 2011;342:c5258

59 Gillespie-Lynch K, Brooks PJ, Someki F, et al. Changing college students' conceptions of autism: An online training to increase knowledge and decrease stigma. J Autism Dev Disord 2015;45 (08):2553-2566

60 Johnson N, Van Hecke A. Increasing autism awareness in innercity churches: A brief report. J Pediatr Nurs 2015;30(06):e63-e69

61 Chown N. 'Do you have any difficulties that I may not be aware of?'A study of autism awareness and understanding in the UK police service Int J Police Sci Manag 2010;12(02):256-273 